\section{EXPLORING DESIGN PATTERNS FOR SUSTAINABLE BEHAVIOUR}

\author{
Dan Lockton \\ Brunel University, UK and WMG, University of Warwick, UK
}

David Harrison

Brunel University, UK

Neville A. Stanton

University of Southampton, UK

\begin{abstract}
Products and services explicitly intended to influence users' behaviour are increasingly being proposed to reduce environmental impact and for other areas of social benefit. Designing such interventions often involves adopting and adapting principles from other contexts where behaviour change has been studied. The 'design pattern' form, used in software engineering and $\mathrm{HCl}$, and originally developed in architecture, offers benefits for this transposition process.

This article introduces the Design with Intent toolkit, an idea generation method using a design pattern form to help designers address sustainable behaviour problems. The article also reports on exploratory workshops in which participants used the toolkit to generate concepts for redesigning everyday products-kettles, curtains, printers and bathroom sinks/taps-to reduce the environmental impact of use. The concepts are discussed, along with observations of how the toolkit was used by participants, suggesting usability improvements to incorporate in future versions.
\end{abstract}

KEYWORDS: user behaviour, design tools, design methods, ecodesign, idea generation

\section{INTRODUCTION}

Design for sustainable behaviour (Bhamra et al, 2011; Lilley, 2009) and other areas of 'design for behaviour change' and 'persuasive technology' (Fogg, 2003) represent a burgeoning field of current investigation and practice (e.g. Zachrisson et al, 2011, Tromp et al, 2011, Thorpe, 2010; Davis, 2010; van Dam et al, 2010; Froehlich et al, 2010; Matsuhashi et al, 2009; Wever et al, 2008; Lockton et al, 2008; Rodriguez \& Boks 2005). Designers, politicians, economists, social marketers, computer scientists and social scientists-and companies with an eye on corporate social responsibility-are initiating a diverse array of new and redesigned products and services aimed at influencing people's behaviours in many contexts, drawing on principles from human-computer interaction, ergonomics, architecture, social and cognitive psychology and behavioural economics (among other disciplines).

In the case of sustainability, the justification is compelling: for many energy-using products (e.g. white goods), point-of-use behaviour (Elias et al, 2009) comprises a significant determinant of the use phase of the life cycle. Dietz et al (2009) estimate that $20 \%$ of direct household $\mathrm{CO}_{2}$ emissions in the US could be saved through behaviour change, "with little or no reduction in household well-being," while Wood and Newborough (2003) and McCalley and Midden (2002) cite studies in the UK, US and the Netherlands giving $26-36 \%$ as the proportion of home energy usage due to user behaviour decisions. As Chapman (2009: p. 29) puts it, 'the sustainability crisis is a behavioural issue, and not one simply of technology, production, and volume'. An approach emphasizing the power of design to influence 
behaviour in this context is being incorporated into design curricula (e.g. Lilley \& Lofthouse, 2009) and its ethical implications debated (e.g. Pettersen \& Boks, 2008).

Understanding how designers' decisions affect users' behaviour, and what to do about it, is central to much current discussion in fields such as service design (e.g. Bisset \& Lockton, 2010; Mager, 2010) and interaction design, e.g. from Blevis (2007: p.508), who notes that 'it is easier to state the kinds of behaviours we would like to achieve from the perspective of sustainability than it is to account for how such behaviours may be adequately motivated.' Of course, users will not always behave how designers intend or expect them to (Kanis, 1998; Stanton \& Baber, 2002; Redström, 2005), even as designers attempt to 'script' behaviour (Akrich, 1992; Jelsma \& Knot, 2002).

The entry of designers into the 'behaviour business', as Frog Design's Robert Fabricant (2009) has called it, accords with Herbert Simon's assertion that 'everyone designs who devises courses of action aimed at changing existing situations into preferred ones' (Simon, 1981: p.129)—we should not be surprised by it. For example, many of the higher-profile projects placing design in a position of social responsibility, such as the Design for Patient Safety and Design Against Crime initiatives in the UK (Cooper, 2005) inherently involve seeking to influence human behaviour in certain contexts, even if this is not explicitly stated as the focus of the projects.

Theory and practice on behaviour-influencing design have been developed enough in particular domains to allow the production of 'how-to' guides (e.g. Grout, 2007 in medical design; Crowe, 2000 in architectural design against crime; Chak, 2003 in persuasive website design), but while elegant approaches such as Niedderer's (2007) performative objects hold interdisciplinary promise, there is little available as a resource to assist designers working on 'behaviour' problems across a broader set of domains, transposing ideas from one domain to another.

One approach, which the authors have taken, is to provide an inspiration guide or toolkit for brainstorming, drawing on examples and insights from different (mainly psychological) disciplines which are relevant to influencing behaviour. As Eckert \& Stacey (2000: p.525) put it, 'sources of inspiration play a number of important roles in design thinking, as definitions of context, triggers for idea generation, and as anchors for structuring designers' mental representations of designs.'

The question this work seeks to investigate is, essentially, 'How can behavioural insights be brought together as an idea generation toolkit for designers working to influence more environmentally and socially beneficial behaviour?'

\section{A DESIGN PATTERN APPROACH}

Both within and without design practice, a variety of 'creative thinking' techniques are commonly used to generate novel ideas as part of problem-framing and -solving processes, often in group workshops, but also individually. Two contrasting approaches are Eno \& Schmidt's Oblique Strategies (1975), an intentionally unstructured card deck of provocative statements and questions, and TRIZ (e.g. Gadd, 2011), a highly structured innovation and technical problem-solving method derived from the study of patent literature. In between, perhaps, are tools which offer inspiration through 'lateral thinking' processes (e.g. de Bono, 1972). Card-form tools such as IDEO's Method Cards (2003) often address this phase of the design process, either through acting as 'ideation decks' (Golembewski, 2010) or by suggesting appropriate design research methods or approaches to help frame the problem better.

A format widely used in human-computer interaction $(\mathrm{HCl})$, primarily in interface and web design, is that of the design pattern, which describes a form of presenting a situation, and/or possible solutions, in a structured way. The form, via adoption in software engineering in the late 1980s, stems ultimately from architecture: Alexander et al's (1977) A Pattern Language, which covers the design and layout of buildings, towns and communities. Patterns are essentially recurring problem-solution instances, described in a referenceable way which 
enables practitioners to recognize the situation. A typical design pattern in $\mathrm{HCl}$, such as those used by Tidwell (2006) and Crumlish \& Malone (2009), comprises a short title for the pattern (e.g. 'Colour-coded sections' for an interface), a photograph, screenshot or diagram illustrating a very clear or prototypical example of the pattern, and a description of the pattern in a 'What / When / Why / How?' format, explaining the circumstances or situations when the pattern is useful, and details of its implementation. They are presented either on paper or onscreen.

Patterns are not primarily about idea generation, at least not in the forms generally presented, instead being more of a reference. However, where there are multiple possible solutions to a problem, and the principles are abstract enough to require some adaptation or translation to see how they might be applied to the problem in question, sets of patterns could be part of an idea generation process.

\section{APPL YING THE PATTERN FORM TO DESIGN FOR SUSTAINABLE BEHAVIOUR}

The pattern form can help a designer recognize that a 'new' problem situation is similar or analogous to one encountered (and solved) previously elsewhere, even in a different context. This makes them a useful format for cross-disciplinary transfer. Where there are not yet widely accepted 'design solutions' for different behavioural problems, a toolkit based on the pattern form will necessarily be something which suggests possible solutions rather than giving direct 'Use this when...'-style instructions; elements of the pattern form can be usefully applied where they offer advantages, but can be adapted to the idea generation context.

Using elements of the pattern form, the authors have developed the Design with Intent toolkit, which aims to make the 'design for sustainable behaviour' idea generation process easier: helping designers and other stakeholders generate behaviour-changing design concepts, through presenting examples and insights from different disciplines. It is effectively a 'suggestion tool' to help a form of directed brainstorming.

Lawson (2004) uses the term 'gambits' to describe the repertoire of strategies that designers acquire over time, emphasizing the importance of the process of recognizing when each might be appropriate, and this is the angle taken with the toolkit-it aims to be a collection of design gambits for behaviour change. Fincher (1999: p.331) notes that 'the pattern form is singularly well adapted for the sharing of good practice between practitioners,' and certainly in $\mathrm{HCl}$, patterns have been used as a pedagogical tool (e.g. Borchers, 2002; Kotzé et al, 2006) for students or novices learning about the discipline. In this sense, the toolkit could also serve as a teaching tool via its use in workshop-type sessions.

While described in more detail in Lockton et al (2010a), the toolkit will be outlined here to provide background for the workshops described later in this paper.

\section{DESIGN WITH INTENT: A TOOLKIT FOR BEHAVIOUR CHANGE}

The toolkit has been developed via an iterative, participatory process, running workshops with students and designers throughout its development to understand how it is being used and how to improve its structure and content. The patterns were extracted-and abstracted-from an ongoing literature review of treatments of human behaviour in a range of disciplines, together with suggestions from readers of the project's blog, and workshop participants. Two versions, v.0.9 and v.1.0, have been publicly released (Lockton et al, 2009b; 2010b), in print and online (Figures 1 and 2), and these will be briefly described here.

[Figures 1, 2, 3, 4 \& 5 near here please] 
Table 1. The Design with Intent toolkit lenses and patterns, for v.0.9 and v.1.0.

\section{Lenses}

\section{Architectural (v.0.9 \& v.1.0)}

The Architectural Lens draws on techniques used to influence user behaviour in architecture, urban planning and related disciplines such as traffic management and crime prevention through environmental design

\section{Errorproofing (v.0.9 \& v.1.0)}

The Errorproofing Lens represents a worldview treating deviations from the target behaviour as 'errors' which design can help avoid, either by making it easier for users to work without making errors, or by making errors impossible in the first place.

\section{Persuasive (v.0.9) / Interaction (v.1.0)}

All the patterns are really about interaction design in one form or another, but the Persuasive / Interaction Lens brings together some of the most common design elements of interfaces where users' interactions with the system affect how their behaviour is influenced, including from the growing field of Persuasive Technology (Fogg, 2003)

\section{Visual (v.0.9) / Perceptual (v.1.0)}

The Visual / Perception Lens combines ideas from product semantics, ecological psychology and Gestalt psychology about how users perceive patterns and meanings as they interact with the systems around them

\section{Cognitive (v.0.9 \& v.1.0)}

The Cognitive Lens draws on research in behavioural economics and cognitive psychology looking at how people make decisions, and how this is affected by 'heuristics' and 'biases'. If designers understand how users make interaction decisions, that knowledge can be used to influence interaction behaviour. Equally, where users often make poor decisions, design can help counter this.

\section{Security (v.0.9 \& v.1.0)}

The Security Lens represents a 'security' worldview, i.e. that undesired user behaviour is something to deter and/or prevent though 'countermeasures' designed into products, systems and environments, both physically and online, with examples such as digital rights management.

Ludic (v.1.0)

Games are great at engaging people for long periods of time, influencing people's behaviour through their very design. The Ludic Lens includes a number of techniques for influencing user behaviour that can be derived from games and other 'playful' interactions, ranging from basic social psychology mechanisms such as goal-setting, to common game elements such as scores and levels.

\section{Machiavellian (v.1.0)}

The Machiavellian Lens comprises design patterns which, while diverse, all embody an 'end justifies the means' approach. This may be unethical, but is nevertheless commonly used to control and influence consumers through advertising, pricing structures, planned obsolescence, lock-ins and so on.

\section{Patterns (v.0.9)}

Material properties;

Movement \& oscillation;

Orientation; Positioning \&

layout; Removal;

Segmentation \& spacing

Conditional warnings:

Defaults; Extra step;

Interlock; Lock-in \& lock-

out; Partial self-

correction; Portions:

Specialized affordances

\section{Computers as social}

actors; Feedback through

form; Kairos; Operant

conditioning; Reduction;

Respondent conditioning;

Self-monitoring;

Simulation \&

feedforward; Tailoring; Tunnelling

Colour \& contrast;

Implied sequences;

Metaphors; Perceived

affordances; Possibility

trees; Prominence \&

visibility; Proximity \&

similarity; Watermarking

\section{Affective engagement;}

Authority; Commitment \& consistency; Framing; Reciprocation; Scarcity; Social proof
Patterns (v.1.0)

Angles; Converging \& diverging

Conveyor belts; Feature deletion;

Hiding things; Material Properties;

Mazes; Pave the cowpaths;

Positioning; Roadblock; Segmentation \& spacing; Simplicity

Are you sure?; Choice editing Conditional warnings; Defaults; Did you mean?; Interlock; matched affordances; Opt-outs; Portions; Task lock-in/out

Feedback through form; Kairos; Partial completion; Peer feedback; Progress bar; Real-time feedback; Simulation \& feedforward;

Summary feedback; Tailoring; Tunnelling \& wizards
(A)symmetry; Colour associations; Contrast; Fake affordances; Implied sequences; Metaphors; Mimicry \& mirroring; Mood; Nakedness; Perceived affordances; Possibility trees; Prominence; Proximity \& grouping; Seductive atmospherics; Similarity; Transparency;

Watermarking

Assuaging guilt; Commitment \& consistency; Decoys; Desire for order; Do as you're told; Emotional engagement; Expert choice;

Framing; Habits; Personality; Provoke empathy; Reciprocation; Rephrasing \& renaming; Scarcity; Social proof

\section{Atmospherics;}

Surveillance; Threat of damage; What you have; What you know or can do; What you've done; Where you are; Who you are

\section{Coercive atmospherics;}

Peerveillance; Sousveillance;

Surveillance; Threat of injury; Threat to property; What you can do; What you have; What you know; What you've done; Where you are; Who or what you are

Challenges \& targets; Collections; Leave gaps to fill; Levels; Make it a meme; Playfulness; Rewards; Roleplaying; Scores; Storytelling; Unpredictable reinforcement

Anchoring; Antifeatures \& crippleware; Bundling; Degrading performance; First one free; Forced dichotomy; Format lock-in/out, Functional obsolescence; I cut, you choose; Poison pill; Serving suggestion; Slow/no response; Style obsolescence; worry resolution 
In each version, a range of design patterns for influencing behaviour are described and illustrated, grouped into 'lenses'-categories which provide different disciplinary 'worldviews' on behaviour change, challenging designers to think outside the immediate frame of reference suggested by the brief (or the client), and helping with transposing ideas between domains. The lenses (described in Table 1) are not intended to be ontologically rigorous, but primarily a way of triggering multiple viewpoints within an ideation session, somewhat analogous to the 'Six Thinking Hats' method (de Bono, 1987; Hewitt-Gleeson, 2008), though different in structure. In v.0.9 there are 47 patterns, grouped in six lenses; in v.1.0, this increased to 101, grouped in eight lenses. The increase in pattern numbers, and re-grouping of the lenses, came about primarily as the result of workshops where participants suggested new patterns or clearer classifications. The other main change between v.0.9 and v.1.0 was a different physical format: the posters and information sheets of v. 0.9 were replaced by cards, also as a result of workshop experience (a prototype card version of v. 0.9 had been tested in some workshops; Figure 5 shows these cards).

Figures 3 and 4 shows the form of the pattern descriptions, with the Metaphors pattern from the Visual lens of v.0.9 and the Challenges \& targets pattern from the Ludic lens of v.1.0 as examples. The descriptions used in v.1.0 were simplified from those used in v.0.9, again following feedback from workshop sessions: shortened and rephrased as questions, drawing on the form used by Weinreich (2010), who included a modified version of v.0.9 in her textbook Hands-on Social Marketing, and ultimately from Pólya (1945).

The toolkit was intended to be usable in two different 'modes'-the main inspiration mode and an additional prescription mode, using the same overall set of patterns but with a different way of navigating them (Figure 5). Following a pilot study (Lockton et al, 2009a) with an earlier version, it emerged that the inspiration mode, where designers simply explore the patterns informally, lens by lens, was likely to be the main way the toolkit was used in a brainstorming context. Alternatively, in prescription mode, designers formulate the brief in terms of target behaviours, from a list of 11 provided (Table 2); for each, a subset of applicable design patterns, typically $15-25$ in total, is then presented. Still serving as an inspiration, this mode effectively 'prescribes' patterns which have been applied to more closely analogous problems, somewhat along the lines of TRIZ (e.g. Gadd, 2011). A range of concepts can thus be generated which have at least some precedent in application to a similar kind of behaviour change. The suspicion was that this more structured prescription form would lead to less prolific idea generation than the inspiration mode, given the extra complexity involved with using it, but it was considered worth including as an additional way of using the patterns.

Table 2. Eleven target behaviours provided for the prescription mode, with examples.

\begin{tabular}{|c|c|c|}
\hline \multicolumn{3}{|c|}{ User-system interaction: Influencing interactions between a user and a system } \\
\hline S1 & $\begin{array}{l}\text { The user follows a process or path, doing things } \\
\text { in a sequence chosen by the designer }\end{array}$ & $\begin{array}{l}\text { Customer places order via website without missing out any } \\
\text { steps }\end{array}$ \\
\hline S2 & $\begin{array}{l}\text { The user follows a process or path that's } \\
\text { optimized for those particular circumstances }\end{array}$ & $\begin{array}{l}\text { User only spends as much time as really needed in the } \\
\text { shower }\end{array}$ \\
\hline S3 & $\begin{array}{l}\text { Decision among alternatives: a user's choice is } \\
\text { guided }\end{array}$ & Diners choose healthier meal in office canteen \\
\hline S4 & $\begin{array}{l}\text { Only certain users / groups of users can use } \\
\text { something }\end{array}$ & Only users who know PIN can access bank account via ATM \\
\hline S5 & $\begin{array}{l}\text { Only users already behaving in a certain way get } \\
\text { to use something }\end{array}$ & $\begin{array}{l}\text { If a driver's travelling below the speed limit, the next set of } \\
\text { traffic lights turn green, otherwise they stay red }\end{array}$ \\
\hline S6 & $\begin{array}{l}\text { No users can use something in a particular way, } \\
\text { regardless of who they are or what they've done } \\
\text { before }\end{array}$ & $\begin{array}{l}\text { Park bench fitted with central armrest to prevent anyone } \\
\text { lying down }\end{array}$ \\
\hline S7 & $\begin{array}{l}\text { Users only get functionality when environmental } \\
\text { criteria are satisfied }\end{array}$ & $\begin{array}{l}\text { Office lighting cannot be switched on if ambient daylight } \\
\text { adequate }\end{array}$ \\
\hline \multicolumn{3}{|c|}{ User-user interaction: Influencing interaction between users and other users, mediated by system } \\
\hline U1 & $\begin{array}{l}\text { Multiple users are kept separate so they don't } \\
\text { affect each other while using a system }\end{array}$ & Traffic follows one-way system into/out of car park \\
\hline $\mathrm{U} 2$ & $\begin{array}{l}\text { Users (and groups of users) do interact with, and } \\
\text { affect each other while using a system }\end{array}$ & $\begin{array}{l}\text { Staff from different departments mix socially in a building's } \\
\text { atrium }\end{array}$ \\
\hline U3 & $\begin{array}{l}\text { Users can't block or dominate a system to the } \\
\text { exclusion of others }\end{array}$ & $\begin{array}{l}\text { Wide pedestrian concourses prevent groups blocking } \\
\text { passage for others }\end{array}$ \\
\hline U4 & Controlled rate of flow or passage of users & $\begin{array}{l}\text { Visitors to popular museum exhibit routed past it slowly on } \\
\text { moving walkway }\end{array}$ \\
\hline
\end{tabular}




\section{GENERATING CONCEPTS USING THE TOOLKIT}

As part of the development process for the toolkit, workshops have been run with design students at universities in the UK (Brunel), the Netherlands (U. Twente) and Norway (NTNU), practising designers at IDEO, Philips Research and Jaguar Land Rover, a local authority (West Sussex County Council), an NHS trust (Brighton \& Sussex University Hospitals) and at both academic and industry conferences.

One set of workshops at Brunel with a group of 16 design students and recent graduates focused on redesigning aspects of four household products to influence more sustainable user behaviour. These are described here to illustrate how the toolkit can be used and the sort of results it can help produce. Each workshop-with participants working in pairs and individually-used both 'conventional' brainstorming and the toolkit. Michl (2002) contends that most commercial design is really redesign of one form or another, and this is the premise on which the briefs (Table 3 ) were presented: redesigning everyday products to help users use them more efficiently. Based on everyday products where user decisions (or lack of decisions) are responsible for a significant proportion of the products' environmental impact, the focus on familiar interactions meant that participants would be able to relate to them as users as well as designers.

Time-constrained workshop situations do not give the participants the chance to research the real contexts in which the products are used, beyond their own experience. Thus, while the process focuses very much on user behaviour, it is abstracted from the 'deep understanding of the target users' (Dong \& Vanns, 2009: p.95) which is central to user-centred design.

\section{RESEARCH QUESTIONS}

It is difficult to assess formally the 'usefulness' of any idea generation method: in practice, they are often used in contexts where there can be no comparable control group. The questions addressed by the Brunel workshops were thus focused on exploring how participants made use of the toolkit, empirically, to uncover insights useful for improving it: How did they apply the patterns to the different briefs? Which aspects were well-understood and which were not? How were the modes used in practice, compared with 'conventional' brainstorming? The workshops also contributed to widening the 'solution space' for the particular briefs.

It is common practice in conventional brainstorming to focus on generating as many ideas as possible, even if unrealistic. IDEO's 'Rules of Brainstorming', prominently displayed in company meeting rooms, are at least partly geared towards this (including 'Go for quantity (not quality): Set an outrageous goal and surpass it')—drawing directly from Osborn's recommendations for brainstorming, 'Quantity is wanted. The greater the number of ideas, the more the likelihood of winners' (Osborn, 1953: p.301).

It was decided to follow this approach and ask participants to 'go for quantity' and record every idea. While the quantity of ideas generated is not a direct proxy for effectiveness, focusing on quantity during the session can help provide other benefits for the participants; as Sutton and Hargadon (1996) suggested in a major ethnographic study of IDEO's brainstorms, the process exposes participants to a diversity of approaches, and provides a non-judgmental forum 'for getting unstuck' through collaborative endeavour. The emphasis on quantity makes it likely that a large number of 'unrealistic' ideas will be generated, and so the 'quality' of the concepts has not been assessed formally, e.g. by an 'expert panel'-this would simply not reflect what participants were asked to do. However, the nature and possibilities of the concepts generated are discussed (see 'The concepts' below). 
Table 3. The four 'design for sustainable behaviour' briefs given to participants. Photos: author

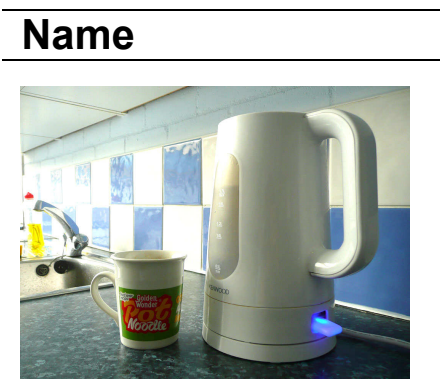

B1 Using the kettle more efficiently

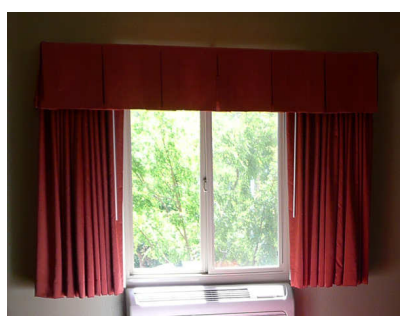

B2 Closing curtains at night

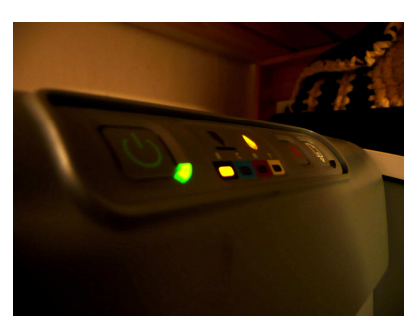

\section{B3 Printing more efficiently}

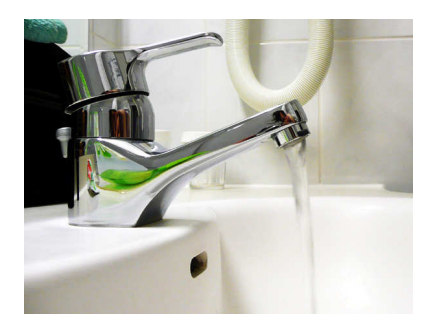

B4 Turning off the tap

Text of brief
electric kettle.

There's a tendency to fill it up with much more water than is necessary for a mug or cup of coffee / tea / etc. Sometimes it's because it's easier to re-boil it all each time than going to fill the kettle up from the tap, but other times it's because it's too difficult to judge how much water's actually needed. And the more water, the longer it takes to boil, too (wasting our time as well as money)

DEFRA estimates that the amount of electricity wasted every year by overfilling kettles in the UK is enough to power all our street lighting (Product Creation, n.d.). So it's a big problem, even though kettles themselves are quite efficient at boiling water.

How could you, as a designer, improve the design of electric kettles to influence - or help - users fill or boil them more efficiently?

Lots of energy is wasted when people forget or can't be bothered to close curtains at night.

The Energy Saving Trust (2003) estimates that $20 \%$ of all household heat in the UK is lost through windows - making sure the curtains / blinds / shutters are closed at night can be a big help here. It can save householders money and doesn't (necessarily) require special extra equipment. For some people, such as the elderly or disabled, closing the curtains may currently be difficult (e.g. if furniture is in the way, or they are too awkward to reach).

How could you, as a designer, improve the design of curtains, or windows / frames / etc, to remind - or help users to close them when it gets dark, or at some point in the evening?

Many people waste paper, ink / toner, energy and time printing unwanted or unnecessary pages.

A Lexmark report found that US government employees each waste on average 2,520 printed pages per year-around $35 \%$ of what they print (Lexmark, 2009). Sometimes prints don't come out how we expect; other times we accidentally print multiple copies instead of one, and so on. This is to a large extent a design problem-users don't think about the options presented by print dialogue boxes, print previews, etc, because of the way the options are presented.

How could you, as a designer, improve the design of printers or printer software to influence or help users print more efficiently (and effectively)?

A lot of people leave the tap running while brushing their teeth.

It might not seem like a major problem, but as water becomes scarcer and the costs of treating it get higher, this sort of mindless waste will become more obvious. Rough calculations based on empirical observations suggest that 2 gallons (9 litres) per person per day would be saved by only running the tap briefly to wet and rinse the brush at the start and end of the process.

While the wasted water could be recycled as part of a 'grey water' system, it would seem better to try to influence people not to waste the water in the first place.

How could you, as a designer, improve the design of taps I sinks / bathrooms / toothbrushes (etc) to influence users to turn off the tap while they're brushing their teeth?
Maximum impact (est.)

1.27 TWh per year reduction in UK electricity demand (Product Creation, n.d.)

Up to $20 \%$ reduction in UK household heating energy demand (Energy Saving Trust, 2003)

\section{2,500 pages per} person per year reduction in printing waste (Lexmark, 2009)

\section{3,200 litres per person per year reduction in water usage (authors' estimate)}

\section{FOUR WORKSHOP EXERCISES}

There were four workshop exercises, presented in an order simulating how the toolkit might be used in the real world as a designer becomes more familiar with it-conventional brainstorming, followed by a free-form exploration of the toolkit patterns (the inspiration mode), then a guided introduction to the more focused prescription mode, and finally a selfguided use of the prescription mode. Each exercise lasted 15 minutes, plus reading time and discussion time afterwards. In the prescription mode exercises, the brief was explicitly matched to a target behaviour (Table 2) and so to a subset of relevant patterns, and participants were asked to bear this in mind while thinking of ideas. So, for brief B2 (Curtains), 
the target behaviour $\mathrm{S} 1$ ('The user follows a process or path, doing things in a sequence chosen by the designer') was given, providing a prescribed starting point for the patterns to look at, and a focus (getting people to close the curtains as part of a sequence or routine every evening). In the second prescription mode exercise, participants were given the full list of target behaviours and asked to decide for themselves on the target behaviour(s) most relevant to the brief given.

The briefs-in different orders-were revealed in sequence as part of a workbook, and participants were asked to note / sketch as many concepts as possible using paper and PostIt notes; it was emphasized that it was the toolkit being investigated rather than the participants' ability, and that every idea should be recorded, even if not favourable. Pairs used something close to a think-aloud discussion method (Lewis \& Rieman, 1994) with each other, explaining their thoughts together as they proceeded.

The toolkit-v.0.9 was used-was not visible for the conventional brainstorming exercise, but when revealed was presented via a poster (Figure 1) and accompanying sheets. For the prescription mode exercises, a diagram mapping target behaviours to relevant patterns was revealed. Afterwards, the concepts were discussed between the facilitator and participants, along with feedback on usability aspects of the toolkit.

After the workshops, the concepts generated were reviewed and any not specifically about influencing user behaviour via product redesign (e.g. just improving the efficiency of a product, or advertising campaigns telling people to save energy) were set aside. These are valuable contributions to design for sustainability, and it was expected that some would arise as a 'freewheeling' corollary of ideation, but they fall outside the intended scope of the toolkit.

[Figures $6 \& 7$ near here please]

\section{THE CONCEPTS}

Table 4 summarizes some of the (subjectively) most interesting concepts generated by participants using the toolkit. Some of the ideas suggested do already exist in a similar form, either on the market or as concepts-such as the two-tank EcoKettle and transparent Kenwood Energy Sense kettle, GreenPrint printing software which offers the ability to choose parts of a document to print more easily beforehand, and coloured lighting in the water stream and a meter on the tap (both found in MIT's WaterBot project (Arroyo et al, 2005). However, there are some genuinely novel-and in some cases dramatic (Gargiulo, 2008)-ideas in Table 4, and it is hoped that some of the concepts generated are of interest to others working in the field of design for sustainable behaviour. Figure 7 shows a selection of participants' sketches for B4 (the tap brief)-these are 'idea sketches' to use Pei et al's (2011) terminology.

Many of the concepts in Table 4 involve 'idea creation by analogical transfer' (Stacey et al 2009: p.362; Tseng et al 2008), or metaphors (Casakin, 2006), from 'time to destination' displays on kettles to curtains styled to look like a woollen jumper; drawing analogies 'can bring forth valuable knowledge from a known situation... to the ill-defined design situation at hand' (Leclercq \& Heylighen, 2002: p.287).

One aspect apparent was how participants considered the roots of the problems differentlya process of problem-framing (Schön, 1983; Dorst and Cross, 2001) as part of problemsolving - which led to different kinds of concepts being proposed. In particular, certain concepts started to reveal participants' mental models of 'what users are like' (and what kinds of measures would change their behaviour), for example whether behaviour was better influenced by educating users through the design of a product and the feedback it gives, or by forcing people to operate it in a different way regardless of understanding 'why?'. This issue was considered interesting enough to investigate further in subsequent workshops (Lockton et al, 2012)-the assumptions designers make about the nature of the problems and the 'users' (a category which may well include themselves) in the first place when seeking to influence their behaviour. 
Table 4. A selection of concepts generated by participants using the toolkit, with the patterns noted by participants as inspiration

\begin{tabular}{|c|c|c|}
\hline & Patterns (v.0.9) & Concept \\
\hline \multirow{10}{*}{ 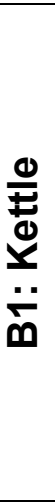 } & Portions & Make kettle fill chamber same diameter as a cup, so the fill level matches it exactly \\
\hline & Self-monitoring; Framing & $\begin{array}{l}\text { Use cup markings, outlines of real-size cups and mugs, or water needed for tasks e.g. how } \\
\text { much to boil for } 1 \text { portion of spaghetti, on scale, as well as litres / fl oz }\end{array}$ \\
\hline & Self-monitoring; Framing & Energy usage or 'Cost per cup' displayed on kettle or base unit \\
\hline & Defaults; Interlock; Extra step & $\begin{array}{l}\text { Kettle where default fill level is } 1 \text { cup, and valve closes when filling, unless explicitly set to a } \\
\text { greater volume; resets itself }\end{array}$ \\
\hline & Segmentation \& spacing & $\begin{array}{l}\text { Two-tank kettle that stores water in one tank but only boils as much as needed in the other, with } \\
\text { rotating chambers and set of transfer ports between }\end{array}$ \\
\hline & $\begin{array}{l}\text { Self-monitoring; Colour \& } \\
\text { contrast }\end{array}$ & Temperature indicator - lights or thermochromic finish - to reduce unnecessary reboiling \\
\hline & Self-monitoring & Kettle beeps as it is filled, once for each cupful \\
\hline & Simulation \& feedforward & Electronic 'Time to ‘destination' scale display on side as kettle is being filled \& boiled \\
\hline & Extra step & $\begin{array}{l}\text { Fill valve 'pauses' while you're filling for every cup / mugful reached, so you have to think before } \\
\text { filling further }\end{array}$ \\
\hline & Prominence \& visibility & $\begin{array}{l}\text { Make kettle transparent or easier to see the 'real' volume of water inside compared with the } \\
\text { small bit typically visible on a narrow scale }\end{array}$ \\
\hline \multirow{10}{*}{ 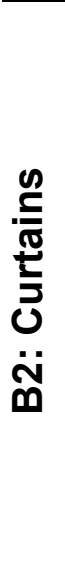 } & Interlock; Defaults & $\begin{array}{l}\text { User can't switch heater on unless the curtains are closed first, or curtains automatically close } \\
\text { by default when heating is switched on }\end{array}$ \\
\hline & Implied sequences & $\begin{array}{l}\text { Number the curtains (large figures on them) so it's obvious when they're not all closed, and } \\
\text { gives people a sequence to follow in going round closing them }\end{array}$ \\
\hline & $\begin{array}{l}\text { Conditional warnings; Colour } \\
\& \text { contrast; Self-monitoring }\end{array}$ & $\begin{array}{l}\text { Illuminated red strip across the window at night to remind you that curtains are still open; or } \\
\text { temperature sensors inside and outside to detect energy loss and suggest closing curtains }\end{array}$ \\
\hline & $\begin{array}{l}\text { Feedback through form; } \\
\text { Operant conditioning }\end{array}$ & $\begin{array}{l}\text { A pattern, picture, or congratulatory message on the curtains so they are more attractive when } \\
\text { closed; or use the curtains as a high-quality projector screen for the TV }\end{array}$ \\
\hline & Kairos & $\begin{array}{l}\text { A beep or loudspeaker suggesting 'Close the curtains' as it starts to get dark, or Public Service } \\
\text { Announcement on TV at appropriate time in the evening 'Close your curtains now' }\end{array}$ \\
\hline & Positioning \& layout; Interlock & Position light switch for the room behind the curtain \\
\hline & Framing; Metaphors & $\begin{array}{l}\text { Curtains promoted as insulation rather than just for shielding light, styled to look like a jumper - } \\
\text { warm, woollen material - that actually zip snugly together to close them }\end{array}$ \\
\hline & Social proof & $\begin{array}{l}\text { Low-powered LEDs reflecting on the outside of curtains to indicate to other people (neighbours) } \\
\text { that the house's curtains are closed (so yours should be too) }\end{array}$ \\
\hline & Orientation & Curtain rail angled in a V-shape so the curtains close more easily than they open \\
\hline & $\begin{array}{l}\text { Material properties; Affective } \\
\text { engagement }\end{array}$ & $\begin{array}{l}\text { Windows with glow-in-the-dark spooky face on them, so it is scary/unpleasant at night unless } \\
\text { curtains closed }\end{array}$ \\
\hline \multirow{10}{*}{ 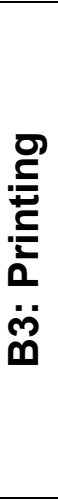 } & Reduction; Tunnelling & Simplify the usability of the print dialogue for different choices; use wizards for common tasks \\
\hline & $\begin{array}{l}\text { Segmentation \& spacing; } \\
\text { Portions }\end{array}$ & $\begin{array}{l}\text { Extra tray for used / scrap paper to be easily re-used for draft prints; or extra A5 / small size } \\
\text { paper tray for printing smaller items or drafts }\end{array}$ \\
\hline & Defaults & Make duplex (double-sided) or 2-up printing the default setting \\
\hline & $\begin{array}{l}\text { Simulation \& feedforward; } \\
\text { Interlock }\end{array}$ & $\begin{array}{l}\text { Better Print Preview window showing exactly what it's going to look like when printed, won't print } \\
\text { unless it's confirmed }\end{array}$ \\
\hline & Metaphors; Self-monitoring & Use a tree being cut down to a stump gradually as a metaphor for paper usage \\
\hline & $\begin{array}{l}\text { Segmentation \& spacing; } \\
\text { Defaults }\end{array}$ & $\begin{array}{l}\text { Make it easy to choose and scale the parts of a document you actually want to print; default for } \\
\text { email printing should be to leave off signature and previous correspondence }\end{array}$ \\
\hline & Self-monitoring; Scarcity & $\begin{array}{l}\text { Speedometer or fuel gauge-style display on-screen, showing how quickly you're using } \\
\text { resources and how much paper / ink is left }\end{array}$ \\
\hline & Extra step & Move the higher quality settings to 'Advanced' tab \\
\hline & $\begin{array}{l}\text { Surveillance; Social proof; } \\
\text { Positioning \& layout }\end{array}$ & $\begin{array}{l}\text { In an office, position printers where everyone can see them, with a display (e.g. a pie chart) } \\
\text { indicating who's printing the most and what settings they're using }\end{array}$ \\
\hline & Extra step; Kairos & $\begin{array}{l}\text { Require user to go through every step of process in order with confirmation at each stage - a } \\
\text { dialogue that actually asks the user 'Do you want double-sided?' etc at right moment }\end{array}$ \\
\hline \multirow{10}{*}{ 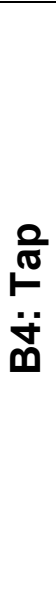 } & $\begin{array}{l}\text { Defaults; Feedback through } \\
\text { form }\end{array}$ & $\begin{array}{l}\text { Sink where the plug is, by default, closed, or a sink that is very flat / shallow: users will see the } \\
\text { amount of water being wasted quickly }\end{array}$ \\
\hline & Where you are & Proximity sensor so tap only on when hands underneath \\
\hline & Defaults; Portions & $\begin{array}{l}\text { Gas tap-style taps that spring to the off position when not in use, or 'Dual-flush' tap that turns } \\
\text { left for teeth, right for continuous flow }\end{array}$ \\
\hline & $\begin{array}{l}\text { Self-monitoring; Framing; } \\
\text { Scarcity }\end{array}$ & $\begin{array}{l}\text { Meter showing water use instantaneously when tap is on; or cumulative meter for water usage } \\
\text { over course of day or week; scale could be framed in everyday measure, e.g. cups }\end{array}$ \\
\hline & $\begin{array}{l}\text { Threat of damage; What } \\
\text { you've done }\end{array}$ & Tap that squirts user in the face through hole in top of spout if left on for too long \\
\hline & $\begin{array}{l}\text { Material properties; Colour \& } \\
\text { contrast }\end{array}$ & $\begin{array}{l}\text { Basin surface changes to bright red like a bloodstain when water has been running on it for too } \\
\text { long }\end{array}$ \\
\hline & Self-monitoring & $\begin{array}{l}\text { A container or tray that catches the water being wasted 'You can see how much you are using, } \\
\text { then you will stop!' }\end{array}$ \\
\hline & Self-monitoring & Beeping or coloured light shining in water indicating flow rate \\
\hline & Metaphors; Portions & $\begin{array}{l}\text { Tap working like an ale pump or old-fashioned water pump, changing the on/off mental model: } \\
\text { a small 'shot' of water }\end{array}$ \\
\hline & Positioning \& layout & $\begin{array}{l}\text { Position the knob at the front of the sink rather than on the tap itself, so that it's closer and } \\
\text { easier to turn off while brushing }\end{array}$ \\
\hline
\end{tabular}


Some variations in how the briefs were addressed might be due to cultural differences, a challenge which Gill (2009) notes as important when designers seek to address users' needs. For example, a number of participants who were international Master's students (primarily from south-east Asia) saw the overfilling problem in brief B1 as being related to limescale ('disgusting') in kettles-something they had not encountered before coming to the UK. In their understanding, overfilling was often done deliberately in an attempt to make sure only boiled water from the 'top' of the kettle chamber (far from the limescaled element) would end up in their drinks. Personal factors also affected the interpretation of brief B2 in discussing behaviour with curtains: in one pair, one participant said that she routinely closed the curtains almost as soon as she got home, for privacy ('people can see me from the other building') while the other contrasted that he 'leave[s] it all open, all night: I don't want to live in a scary atmosphere all the time; that's why there is no social connection between people: all strict, closed off'.

Most concepts were technologically feasible, though without knowledge of how effective they might be at influencing user behaviour in practice. The ideal result of implementing any of the concepts generated would be that the unnecessary environmental impact due to user behaviour is reduced to zero. However the contextual nature of interaction behaviour makes it impossible in many cases to quantify the exact energy savings expected: for example, deciding whether or not someone has printed something as 'optimally' as possible for B3 (the printing brief) is not feasible-the optimal solution would be different for different people and circumstances. Even B1 (the kettle brief), which on the face of it seems clear-cut (any energy put into boiling water which is not used is wasted-1.27 TWh per year according to the Product Creation (n.d.) figures) would be made more efficient by changing behaviour at a system level, for example by altering people's hot-drink consumption habits entirely. It is unrealistic to assume that an energy use display on a kettle would (even if every kettle in the UK were retrofitted or replaced) lead to a saving of anywhere near 1.27 TWh per year (compare the literature on the effectiveness of feedback, e.g. Darby (2006)), but some concepts involving changing the actual affordances and constraints of the kettle design, so that only one portion at a time is transferred or boiled, could have a large effect.

Was there a difference between the concepts arising from conventional brainstorming and those generated using the toolkit? Many ideas recurred for the same brief (from different participants), especially around some of the simpler feedback mechanisms (e.g. lights warning people that the curtains were open, or that the kettle was overfilled). But where concepts were directly related to particular patterns from the toolkit, they only occurred after the toolkit had been used-for example, the use of metaphors and the idea of simulation and feedforward were not present in any of the conventional brainstorming concepts from any participant, but inspired a number of concepts directly once the toolkit was used.

B3, the brief on printing, resulted in the most concepts being generated $(113$, compared with 83,91 and 86 for B1, B2 and B4 respectively) - this might suggest that this issues with printing personally frustrate some of the participants in their everyday jobs and studies in a way which, say, heat loss via uncurtained windows does not. Different participants came up with very different amounts of concepts. The most prolific pair produced nearly three times the number of concepts of the least prolific; some individuals were more productive than some pairs. The inspiration mode exercise resulted in more concepts overall (112) than either conventional brainstorming (84) or the prescription modes (88 and 89), but it was not uniformly better for all participants individually. So a one-size-fits-all approach may not be ideal: it seems worthwhile to provide different ways of using the toolkit.

\section{HOW THE TOOLKIT WAS USED}

Most individual participants did not have time to consider all the relevant patterns for each brief. Some started with one lens and worked through all the patterns before moving onto the next, while others primarily picked patterns which stood out to them-perhaps due to a visually interesting image. In almost all cases, the participants were still working when the end of the session was reached. Pairs generally approached the patterns with each person taking three of the six lenses, noting down some ideas, then explaining the lens and the patterns to his or her partner, and talking together for the rest of the session, building on the initial ideas, 
mutating them into further concepts. (This could be seen as a combination of the first stage of the nominal group technique (Delbecq \& van de Ven, 1971) with conventional face-to-face brainstorming.)

There was no explicit evidence that participants did not understand the idea of transposing design patterns from one discipline to another. However, only a few participants transposed concepts from the Architectural lens to non-physical, system architecture or information architecture situations (e.g., for brief B3, Segmentation \& spacing might have suggested breaking up a document into elements which could be chosen separately to print, with different settings). This suggests that different phrasing for the Architectural lens, or the use of more non-physical examples, might be appropriate for a future iteration of the toolkit.

In the prescription mode exercises, while some participants stuck closely to the target behaviours, most only used these as a starting point. Particularly with pairs, as discussion between the participants threw up new concepts, the target behaviour often seemed to be forgotten. When asked to choose target behaviours themselves, a variety of choices were made, with some participants running through a number of target behaviours and 'testing' how well each seemed to apply to the brief, without actually committing to any-indicating an interest in understanding the problem; there was no consensus apparent, although for B1, B3 and B4 at least some participants did choose the target behaviour that was expected.

It is clear that the target behaviours in the current form are not well-understood, and (based on the quantity of concepts generated) do not appear to be especially useful at the idea generation stage of the design process. It has been suggested that designers-used to being 'creative' on demand-simply do not appreciate a highly structured idea generation method. This might be different for brainstorming with participants for whom it is a less common activity. Particularly at the idea generation stage of a project, when the point is to come up with a large quantity of concepts which can be pruned later, an additional constraint such as the target behaviour is, perhaps, unnecessary.

\section{DISCUSSION AND CONCLUSIONS}

What benefits does this toolkit offer? At this stage in the development of design for sustainable behaviour as a specialism somewhere between ecodesign and interaction design, there are few guides available, thus to some extent the bar is quite low. Compared with other idea generation tools and methods, Design with Intent is focused on a particular approach (behaviour) rather than generating innovative concepts in general, thus it is difficult to compare it directly to tools such as the IDEO Method Cards which have a much broader set of use-cases. One aspect of the toolkit which some workshop participants have considered effective (and commented so) was the use of illustrated, relatively simple examples as part of the 'pattern' form-rather than only using descriptions of the principles themselves. This helped make otherwise abstract or unfamiliar psychological terminology such as 'Social proof' or 'Operant conditioning' relevant in a design context.

Exploratory transposition of methods and ideas from other domains can allow an accessible route into engaging with behaviour change ideas for stakeholders both 'inside' and 'outside' design. For example, Young (2010), discussing the Design \& Behaviour project run by the Royal Society for the encouragement of Arts, Manufactures and Commerce in the UK-in which the Design with Intent toolkit was used in workshops addressing public engagement with the police-emphasizes the importance of drawing on other fields to inspire idea generation in the context of behaviour change for social benefit: 'By looking at how others have used design to influence behaviour it is easier to transpose those ideas to the behaviours that you are trying to change... We need that idea-generating process to help policy makers work with designers, behaviour experts and people [i.e. the public] to make the leap into practice.'

The workshops showed, tentatively, that for many participants, using the toolkit in a free-form inspiration mode-less like TRIZ but more like Oblique Strategies-following conventional brainstorming, helped them generate more concepts for addressing the briefs than conventional brainstorming alone. Using the toolkit in prescription mode was not particularly 
effective in terms of the quantity of ideas generated-although for some, the idea of focusing on a target behaviour provided a useful starting point for thinking about the problem further. This suggests that future versions of the toolkit need to be usable in a variety of different ways by designers and other stakeholders, to suit different contexts.

The most important test of an idea generation method is probably whether it is found useful by its users - whether they choose to use it, or continue to use it, and embed it in their organizational decision-making processes. The workshops described in this article were carried out in a university setting rather than an industrial or public sector context, and the utility and usability of the toolkit in this latter 'real world' situation is essential to its further development. A survey is in progress of early adopters of the toolkit (people who have downloaded it or bought a physical copy) to understand how and why they have used it, and what insights can be extracted to improve it in future iterations.

Designers will play a major part in influencing more sustainable user behaviour as the recognition of its importance becomes increasingly mainstream, both politically and commercially, complementing the hitherto dominant focus on the technological aspects of ecodesign. It will be worthwhile exploring and supporting the processes by which designers generate their ideas in this domain, the challenges around ethical issues, and indeed the shifting boundaries of the role of the designer in a world where user behaviour potentially becomes part of product specifications.

\section{ACKNOWLEDGEMENTS}

The authors express their appreciation to the participants in the studies, and to the Ormsby Trust and Thomas Gerald Gray Charitable Trust, who funded the research. 


\section{REFERENCES}

Akrich, M (1992) 'The De-Scription of Technical Objects'. In Bijker, W \& Law, J (eds.) Shaping Technology/Building Society, 205-224. Cambridge, MA: MIT Press

Alexander, C, Ishikawa, S, Silverstein, M, Jacobson, M, Fiksdahl-King, I \& Angel, S (1977) A Pattern Language. New York: Oxford University Press

Arroyo, E, Bonanni, L \& Selker, T (2005) 'WaterBot: Exploring Feedback and Persuasive Techniques at the Sink'. Proceedings of the 2005 SIGCHI conference on Human Factors in Computing Systems, 631-639

Bhamra, T, Lilley, D \& Tang, T (2011) 'Design for Sustainable Behaviour: Using Products to Change Consumer Behaviour'. The Design Journal, 14(4), 427-445

Bisset, F \& Lockton, D (2010) 'Designing motivation or motivating design? Exploring service design, motivation and behavioural change'. Touchpoint: The Journal of Service Design, 2(1), 14-21

Blevis, E (2007) 'Sustainable Interaction Design: Invention \& Disposal, Renewal \& Reuse'. Proceedings of the 2007 SIGCHI conference on Human Factors in Computing Systems Design Theory, 503-512

de Bono, E (1972) Po: Beyond Yes and No. Harmondsworth: Penguin

de Bono, E (1987) Six Thinking Hats, 2nd edition. Harmondsworth: Pelican

Borchers, J (2002) 'Teaching $\mathrm{HCl}$ Design Patterns: Experience From Two University Courses'. Proceedings of the 2002 SIGCHI conference on Human Factors in Computing Systems: workshop position papers

Casakin, H P (2006) 'Metaphors as an unconventional reflective approach in architectural design'. The Design Journal, 9(1), 37-50

Chak, A (2003) Submit Now: Designing Persuasive Web Sites. Indianapolis: New Riders

Chapman, J (2009) 'Design for (emotional) durability'. Design Issues, 25(4), 29-35

Cooper, R (2005) 'Ethics and Altruism: What Constitutes Socially Responsible Design?' Design Management Review, 16(3), 10-18

Crowe, T D (2000) Crime Prevention Through Environmental Design, 2nd edition. Boston: Butterworth-Heinemann

Crumlish, C \& Malone, E (2009) Designing Social Interfaces. Sebastapol: O'Reilly

van Dam, S S, Bakker, C A \& van Hal, J D M (2010) 'Home energy monitors: impact over the medium-term'. Building Research \& Information, 38(5), 458-469

Darby, S (2006) The Effectiveness of Feedback on Energy Consumption: A review for Defra of the literature on metering, billing and direct displays. Oxford: Environmental Change Institute

Davis, J (2010) 'Generating directions for Persuasive Technology Design with the Inspiration Card Workshop'. Proceedings of Persuasive 2010, 5th International Conference on Persuasive Technology, Copenhagen, 262-273

Delbecq, A L \& van de Ven, A H (1971) 'A Group Process Model for Problem Identification and Program Planning'. Journal of Applied Behavioral Science 7, 466-492

Dietz, T, Gardner, G T, Gilligan, J, Stern, P C \& Vandenberghe, M P (2009) 'Household actions can provide a behavioral wedge to rapidly reduce US carbon emissions'. Proceedings of the National Academy of Sciences 106 (44), 18452-18456

Dong, H \& Vanns, N (2009) 'Designing an Innovative Pill Dispenser: An Undergraduate Level Case Study of Inclusive Design'. The Design Journal, 12(1), 95-116

Dorst, K \& Cross, N (2001) 'Creativity in the design process: co-evolution of problemsolution'. Design Studies, 22(5), 425-437

Eckert, C \& Stacey, M (2000) 'Sources of inspiration: a language of design'. Design Studies $21,523-538$

Elias, E W, Dekoninck, E A \& Culley, S J (2009) 'Designing for "Use Phase” Energy Losses of Domestic Products'. Proceedings of the Institution of Mechanical Engineers Part B Journal of Engineering Manufacture 223 (1), 115-120

Energy Saving Trust (2003) Don't let your home get away with it - media facts. Retrieved 17 September 2010. Available from:

http://www.energysavingtrust.org.uk/uploads/documents/aboutest/homegetawaywithit.pdf

Eno, B \& Schmidt, P (1975) Oblique Strategies: Over 100 worthwhile dilemmas. London: Apollo

Fabricant, R (2009) 'Behaving badly in Vancouver'. Design Mind, February 11 2009. San Francisco: Frog Design. Retrieved 17 September 2010. Available from:

http://designmind.frogdesign.com/blog/behaving-badly-in-vancouver.html 
Fincher, S (1999) 'Analysis of Design: An exploration of Patterns and Pattern Languages for Pedagogy'. Journal of Computers in Mathematics and Science Teaching, 18(3), 331-348

Fogg, B J (2003) Persuasive Technology: Using Computers to Change What We Think and Do. San Francisco: Morgan Kaufmann

Froehlich, J, Findlater, L \& Landay, J (2010) 'The Design of Eco-Feedback Technology'. Proceedings of the 2010 SIGCHI conference on Human Factors in Computing Systems, 1999-2008

Gadd, K (2011) TRIZ for Engineers: Enabling Inventive Problem Solving. Chichester: John Wiley.

Gargiulo, D (2008) Active objects, passive dramas. MDes thesis, Auckland: Unitec. Retrieved 17 September 2010. Available from: http://unitec.researchbank.ac.nz/handle/10652/1291

Golembewski, M (2010) Ideation Decks: A card-based tool designed to help creative practitioners develop project ideas. Horizon DTC report, University of Nottingham

Grout, J (2007) Mistake-Proofing the Design of Health Care Processes. Rockville: Agency for Healthcare Research and Quality

Hewitt-Gleeson, M (2008) 'Dispute with Edward de Bono'. Melbourne: School of Thinking website. Retrieved 17 September 2010. Available from:

http://www.schoolofthinking.org/about/training/10-dfq/the-hats-the-origin-of-the-thinking-hats-

idea

IDEO (2003) IDEO Method Cards: 51 Ways to Inspire Design. Palo Alto: IDEO.

Jelsma, J \& Knot, M (2002) 'Designing environmentally efficient services: a "script" approach'. Journal of Sustainable Product Design, 2(3-4), 119-130.

Kanis, H (1998) 'Usage centred research for everyday product design'. Applied Ergonomics, 29 (1), 75-82.

Kotzé, P, Renaud, K, Koukouletsos, K, Khazaei, B \& Dearden, A (2006) 'Patterns, AntiPatterns and Guidelines - Effective Aids to Teaching $\mathrm{HCl}$ Principles?' Proceedings of HCIEd2006-1: First Joint BCS/IFIP WG 13.1/ICS /EU CONVIVIO HCI Educators' Workshop, Limerick, Ireland

Lawson, B (2004) 'Schemata, gambits and precedent: some factors in design expertise'. Design Studies 25, 443-457.

Leclercq, P \& Heylighen, A (2002) ‘5,8 analogies per hour. A designer's view on analogical reasoning'. Proceedings of AID '02: Artificial Intelligence in Design 2002, 285-304

Lewis, C \& Rieman, J (1994) Task-Centered User Interface Design: A Practical Introduction. Boulder: University of Colorado.

Lexmark (2009) 2009 Government Printing Report: A Closer Look at Costs, Habits, Policies \& Opportunities for Savings. Retrieved 17 September 2010. Available from:

http://www.governmentprintingreport.com

Lilley, D (2009) 'Design for sustainable behaviour: strategies and perceptions'. Design Studies 30, 704-720.

Lilley, D \& Lofthouse, V (2009) 'Sustainable design education: considering design for behavioural change'. Engineering Education: Journal of the Higher Education Academy Engineering Subject Centre, 4(1), 29-41.

Lockton, D, Harrison, D \& Stanton, N A (2008) 'Making the user more efficient: design for sustainable behaviour'. International Journal of Sustainable Engineering, 1(1), 3-8.

Lockton, D, Harrison, D, Holley, T \& Stanton N A (2009a) 'Influencing Interaction: Development of the Design with Intent Method'. Proceedings of Persuasive 2009, 4th International Conference on Persuasive Technology, Claremont, CA

Lockton, D, Harrison, D \& Stanton, N A (2009b) Design for Behaviour Change: The Design with Intent Toolkit v.0.9. Uxbridge: Brunel University.

Lockton, D, Harrison, D \& Stanton, N A (2010a) 'The Design with Intent Method: a design tool for influencing user behaviour'. Applied Ergonomics, 41(3), 382-392.

Lockton, D, Harrison, D, Stanton, N A (2010b) Design with Intent: 101 Patterns for Influencing Behaviour Through Design v.1.0. Windsor: Equifine

Lockton, D, Harrison, D, Stanton, N A (2012) 'Models of the user: designers' perspectives on influencing sustainable behaviour'. Journal of Design Research, 10(1/2), 7-27

Mager, B (2010) 'Editorial: Isn't life always centred around influencing the behaviour of other people?' Touchpoint: The Journal of Service Design, 2(1), 6-7

Matsuhashi, N, Kuijer, L \& de Jong, A (2009) 'A Culture-Inspired Approach to Gaining Insights for Designing Sustainable Practices'. Proceedings of EcoDesign 2009: Sixth International Symposium on Environmentally Conscious Design and Inverse Manufacturing 
McCalley, L T \& Midden, C J H (2002) 'Energy conservation through product-integrated feedback: The roles of goal-setting and social orientation'. Journal of Economic Psychology 23(5), 589-603

Michl, J (2002) 'On seeing design as redesign: an exploration of a neglected problem in design education'. Scandinavian Journal of Design History 12, 7-23

Niedderer, K (2007) 'Designing Mindful Interaction: The Category of Performative Object'. Design Issues, 23(1), 3-17

Osborn, A F (1953) Applied Imagination. Oxford: Scribner's.

Pei, E, Campbell, I \& Evans, M (2011) 'A Taxonomic Classification of Visual Design Representations Used by Industrial Designers and Engineering Designers'. The Design Journal, 14(1), 64-91

Pettersen, I N \& Boks, C (2008) 'The Ethics in Balancing Control and Freedom when Engineering Solutions for Sustainable Behaviour'. International Journal of Sustainable Engineering, 1(4), 287-297.

Pólya, G (1945) How to Solve It. Princeton: Princeton University Press

Product Creation (n.d.) 'Eco Kettle'. Retrieved 17 September 2010. Available from:

http://www.ecokettle.com/aftersales.htm

Redström, J (2005) 'Towards user design? On the shift from object to user as the subject of design'. Design Studies 27, 123-139

Rodriguez, E \& Boks, C (2005) 'How design of products affects user behaviour and vice versa: the environmental implications'. Proceedings of EcoDesign 2005: Fourth International Symposium on Environmentally Conscious Design and Inverse Manufacturing

Schön, D (1983) The Reflective Practitioner: How professionals think in action. London: Temple Smith

Simon, H A (1981) The Sciences of the Artificial. $2^{\text {nd }}$ edition. Cambridge, MA: MIT Press

Stacey, M, Eckert, C \& Earl, C (2009) 'From Ronchamp by Sledge: On the Pragmatics of Object References'. In McDonnell, J \& Lloyd, P (eds.) About: Designing: Analysing Design Meetings. Leiden: CRC Press, 361-379

Stanton, N A \& Baber, C (2002) 'Error by design: methods for predicting device usability'. Design Studies 23, 363-384.

Sutton, R I \& Hargadon, A (1996) 'Brainstorming groups in context: effectiveness in a product design firm'. Administrative Science Quarterly, 41(4), 685-718.

Thorpe, A (2010) 'Design's role in sustainable consumption'. Design Issues, 26(2), 3-16.

Tidwell, J (2005) Designing Interfaces. Sebastopol: O'Reilly.

Tromp, N, Hekkert, P \& Verbeek, P-P (2011) 'Design for Socially Responsible Behavior: A Classification of Influence Based on Intended User Experience'. Design Issues 27(3), 3-19

Tseng, I, Moss, J, Cagan, J \& Kotovsky, K (2008) 'The role of timing and analogical similarity in the stimulation of idea generation in design'. Design Studies 29, 203-221

Weinreicj, N K (2010) Hands-on Social Marketing, $2^{\text {nd }}$ edition. Thousand Oaks: Sage Publications

Wever, R, van Kuijk, J \& Boks, C (2008) 'User-centred Design for Sustainable Behaviour'. International Journal of Sustainable Engineering, 1(1), 9-20

Wood, G \& Newborough, M (2003) 'Dynamic energy-consumption indicators for domestic appliances: environment, behaviour and design'. Energy \& Buildings 35, 821-841.

Young, J (2010) 'RSA Design \& Behaviour - Missing Links', 11 January 2010. Retrieved 17 September 2010. Available from:

http://designandbehaviour.rsablogs.org.uk/2010/01/11/missing-links

Zachrisson, J, Storrø, G \& Boks, C (2011) 'Using a guide to select design strategies for behaviour change; Theory vs. Practice'. Proceedings of EcoDesign 2011 - 7th International Symposium on Environmentally Conscious Design and Inverse Manufacturing, Kyoto, Japan. 


\section{CAPTIONS FOR FIGURES}

Figure 1. The print form of v. 0.9 of the toolkit comprised an A2 poster illustrating two patterns from each of the six lenses, together with additional sheets explaining the other 35 patterns. Figure 3 shows a close-up of the 'Metaphors' pattern from the Visual lens.

Figure 2. The print form of v.1.0 of the toolkit comprised a pack of $101 \mathrm{cards}$ divided into eight colour-coded 'lenses'. Each card illustrated one pattern in the form of a question and example (see Figure 4).

Figure 3. The form of the pattern descriptions in Design with Intent v.0.9, with the Metaphors pattern from the Visual lens as an example.

Figure 4. The form of the pattern descriptions in Design with Intent v.1.0, with the Challenges \& targets pattern from the Ludic lens as an example.

Figure 5. An illustration of the lenses, and a comparison of the inspiration and prescription mode processes.

Figure 6. A selection of images from the workshops.

Figure 7. A selection of participants' sketches for B4 (the tap brief). 


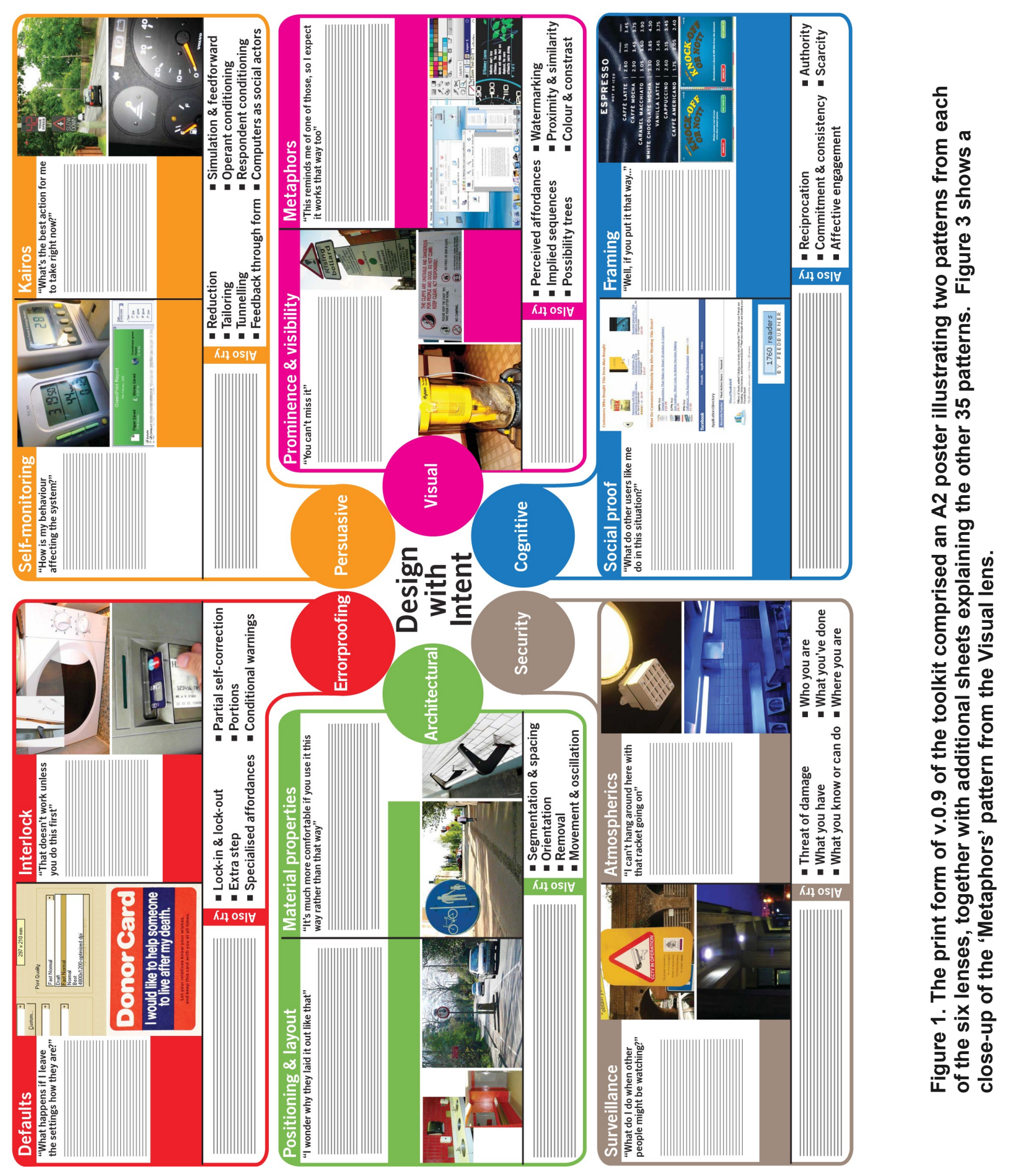




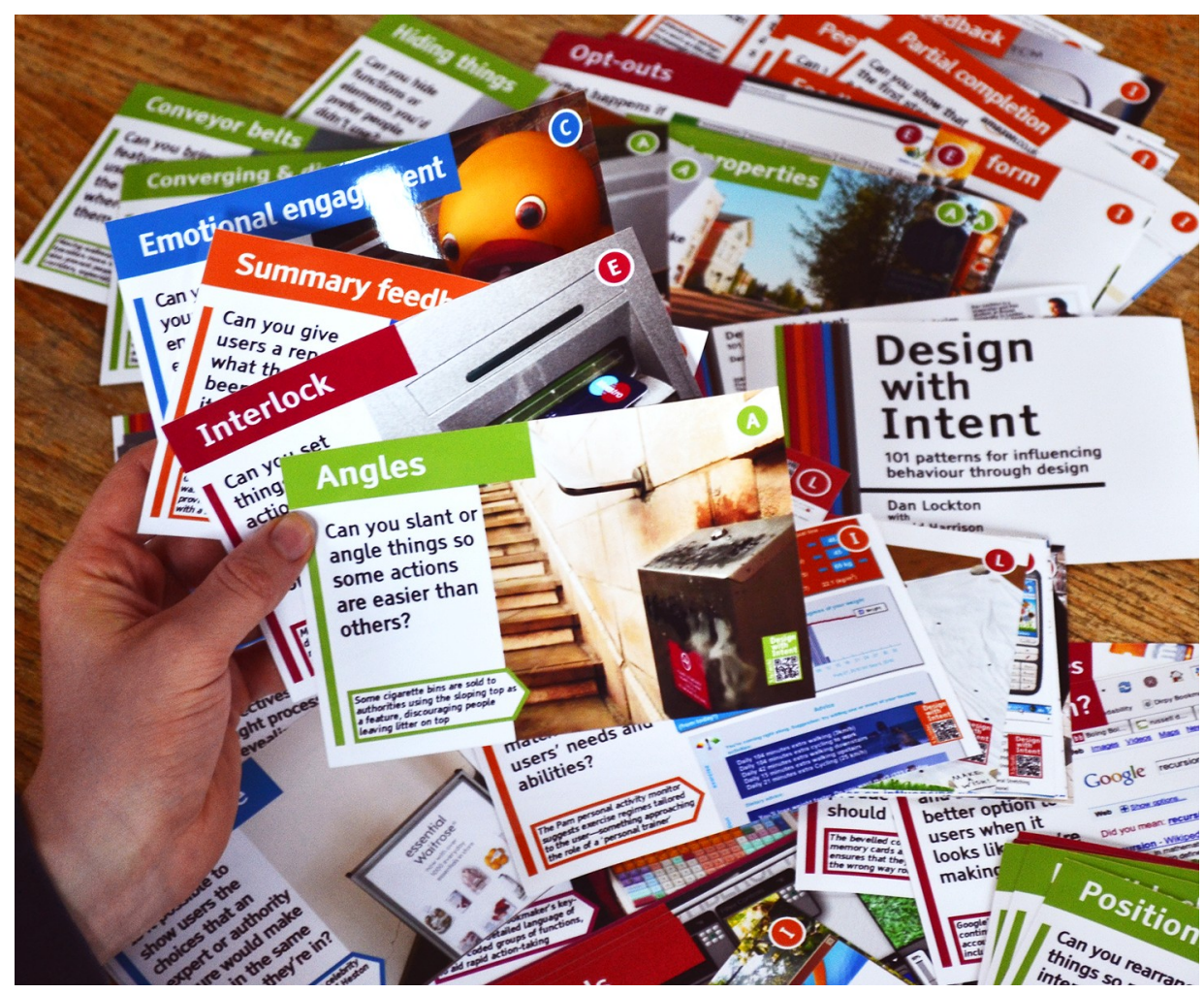

Figure 2. The print form of v.1.0 of the toolkit comprised a pack of 101 cards divided into eight colour-coded 'Ienses'. Each card illustrated one pattern in the form of a question and example (see Figure 4). 
"Tagline"

- Paragraph introducing the pattern

- Paragraph noting pros and cons

Description of examples illustrated

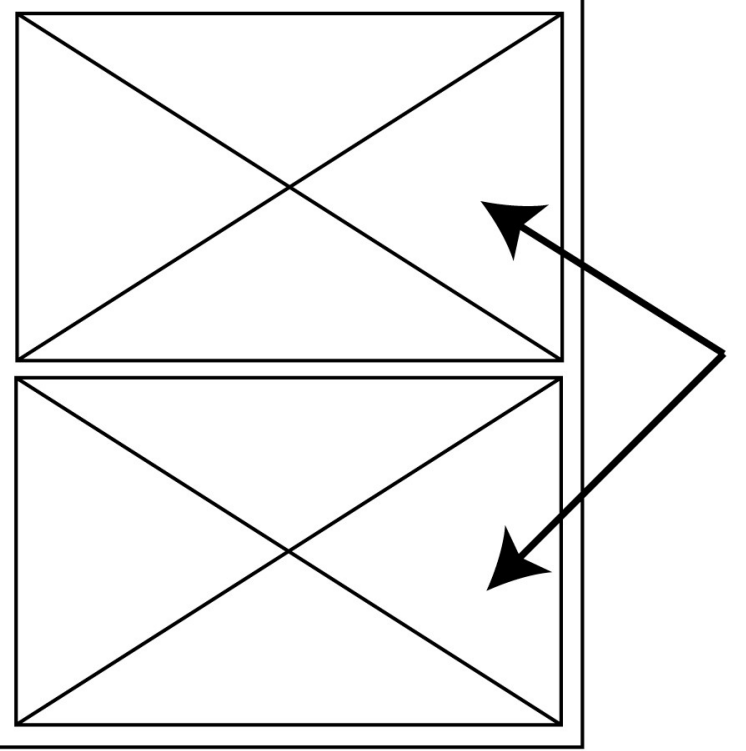

Photographs or screenshots of examples

\section{Metaphors}

\section{"This reminds me of one of those, so I expect it works that way too"}

- Use design elements from a context the user understands in a new system, to imply how it should be used; make it easy for users to understand a new system in terms they already understand

- There's a danger of oversimplification, or misleading users about the consequences of actions, if metaphor use is taken to extremes; it can also trap users in old behaviour patterns

Everyday software interfaces combine hundreds of metaphors, from the 'desktop', 'folders' and 'trash/recycle bin' themselves to the icons used for graphics functions such as zoom (magnifying glass), eyedropper and so on

Ford's SmartGauge uses 'leaves' to represent efficiency of a user's driving style

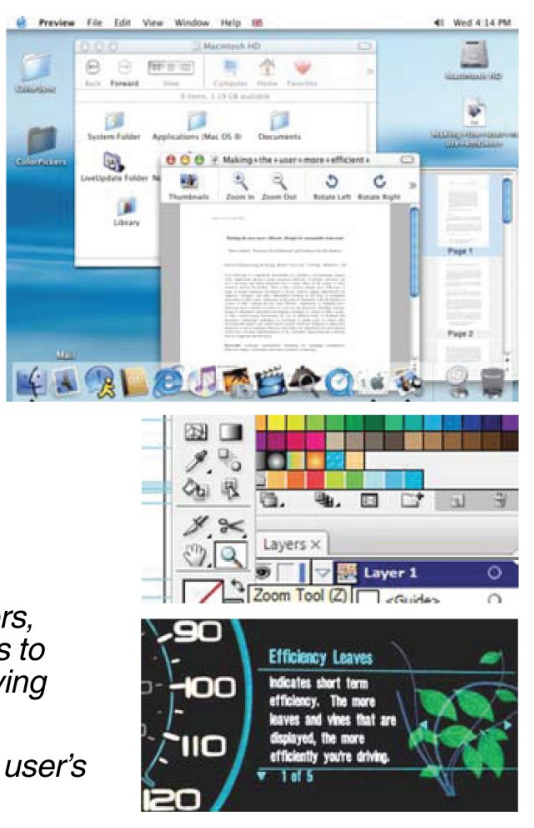

Figure 3. The form of the pattern descriptions in Design with Intent v.0.9, with the Metaphors pattern from the Visual lens as an example. 


\section{Pattern title}

Photograph or introducing the pattern, in 'Can you...?' or 'What would happen if...?' form

Description of
example illustrated

Description of
example illustrated

Question

\section{Challenges \& targets}

\section{What happens if} you set people a challenge, or give them a target to reach through what they're doing?

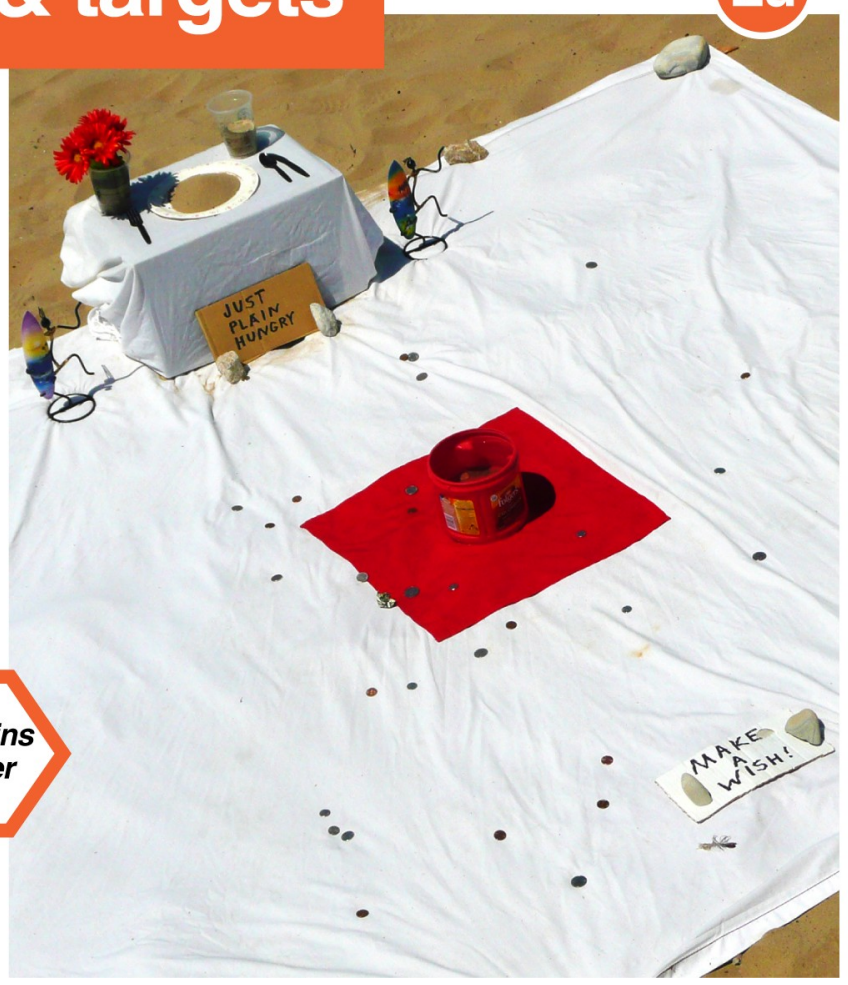

Figure 4. The form of the pattern descriptions in Design with Intent v.1.0, with the Challenges \& targets pattern from the Ludic lens as an example. 


\section{The lenses}

Each 'lens' is a collection of patterns taking a similar viewpoint on how to influence behaviour. See Table 1 (v.0.9: six lenses; v.1.0: eight lenses)

(v.1.0 patterns illustrated)

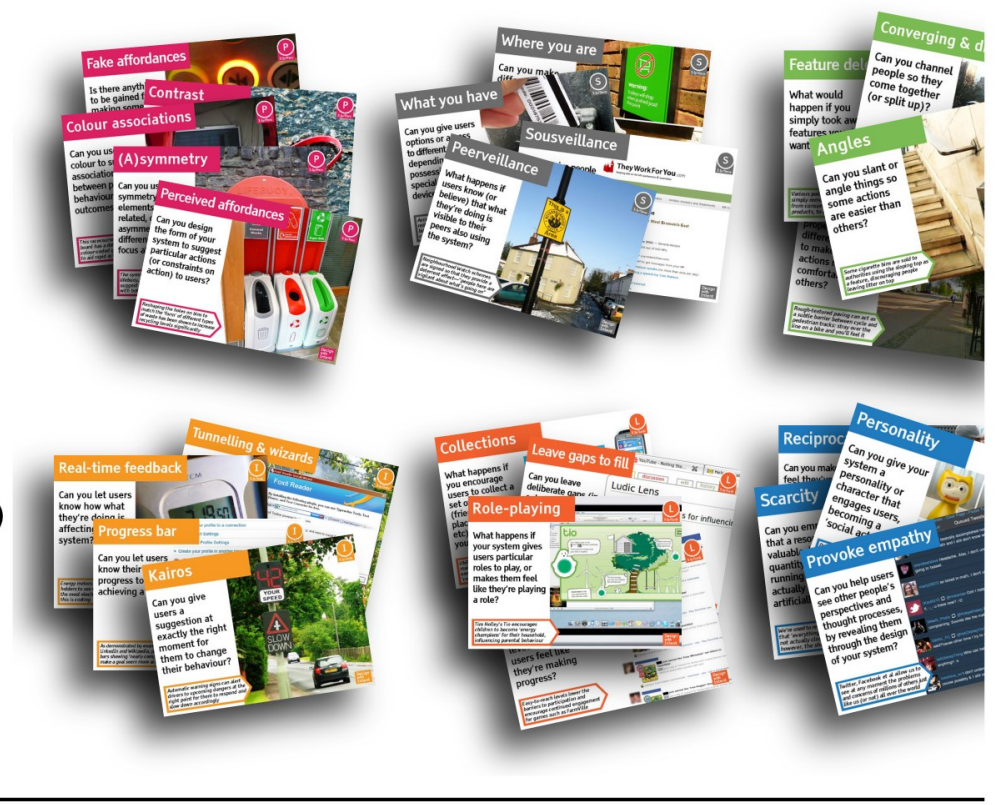

\section{Inspiration mode}

Looking at each lens in turn, ask yourself whether each pattern could be relevant to the problem, and if so, pick it out.

(v.1.0 patterns illustrated)

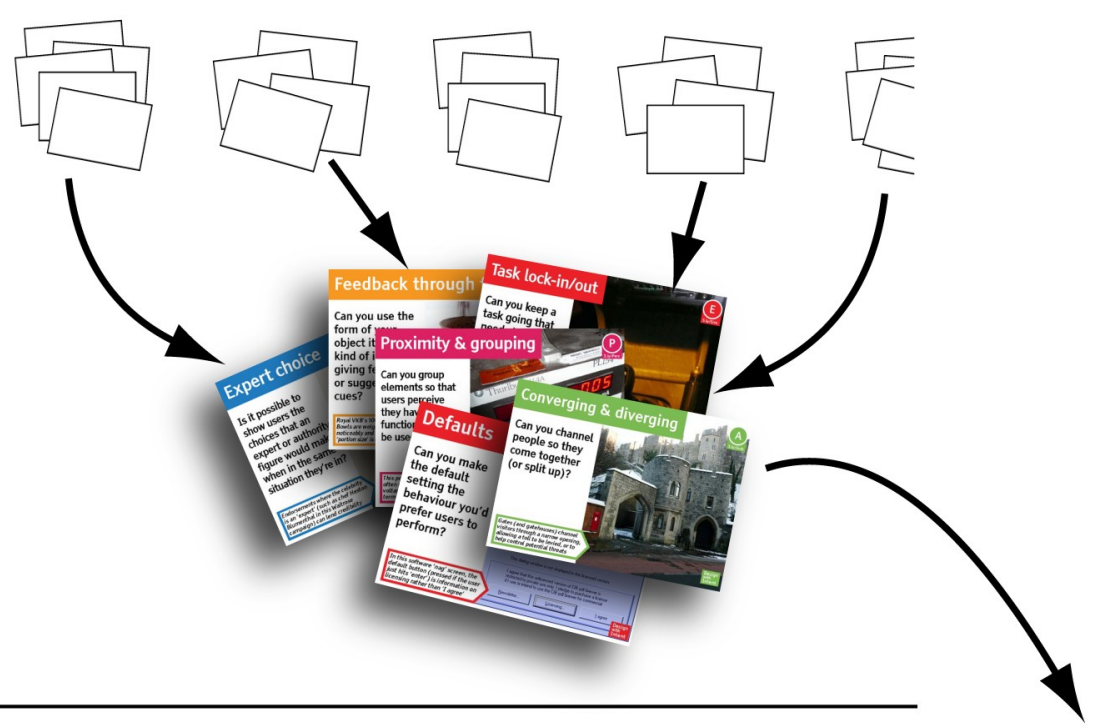

\section{Prescription mode}

Choose desired target behaviour (Table 2) and some appropriate patterns from each lens are suggested.

(v.0.9 patterns illustrated)

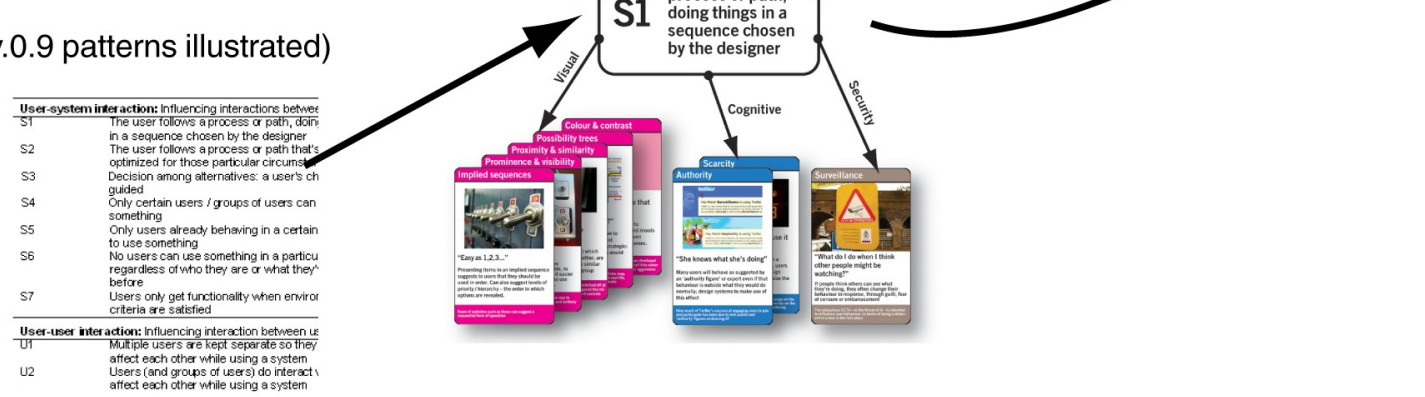

\section{Concept generation}

Try applying the patterns selected to the problem to generate possible concept solutions.

Figure 5. An illustration of the lenses, and a comparison of the inspiration and prescription mode processes. 

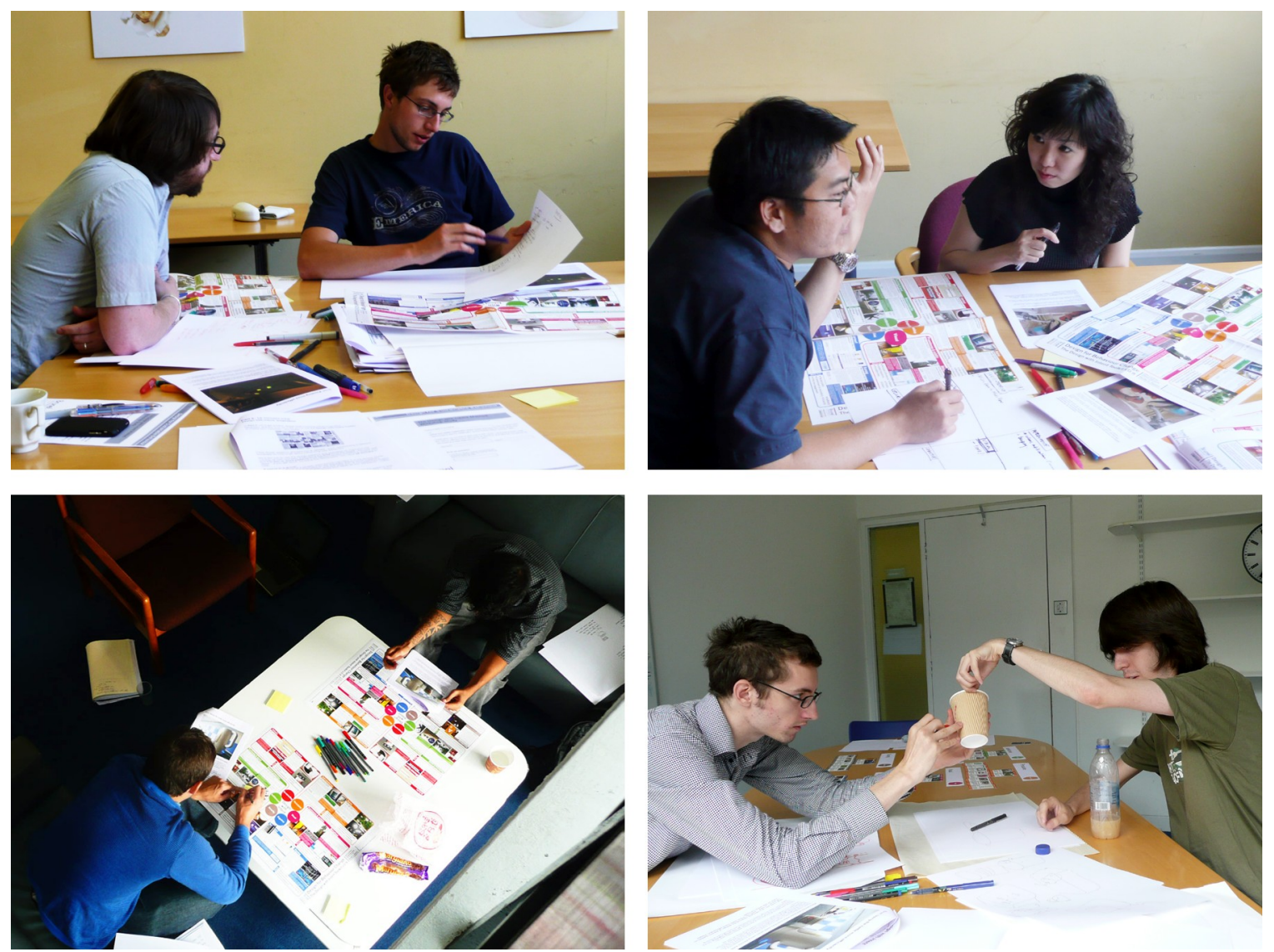

Figure 6. A selection of images from the workshops.

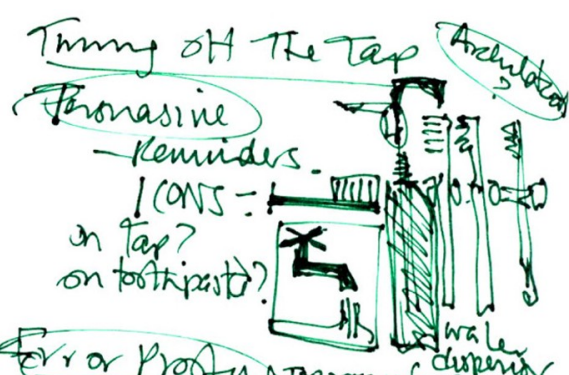
Fr or Prootu tap options for disperio.

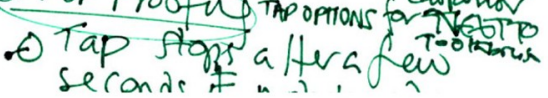
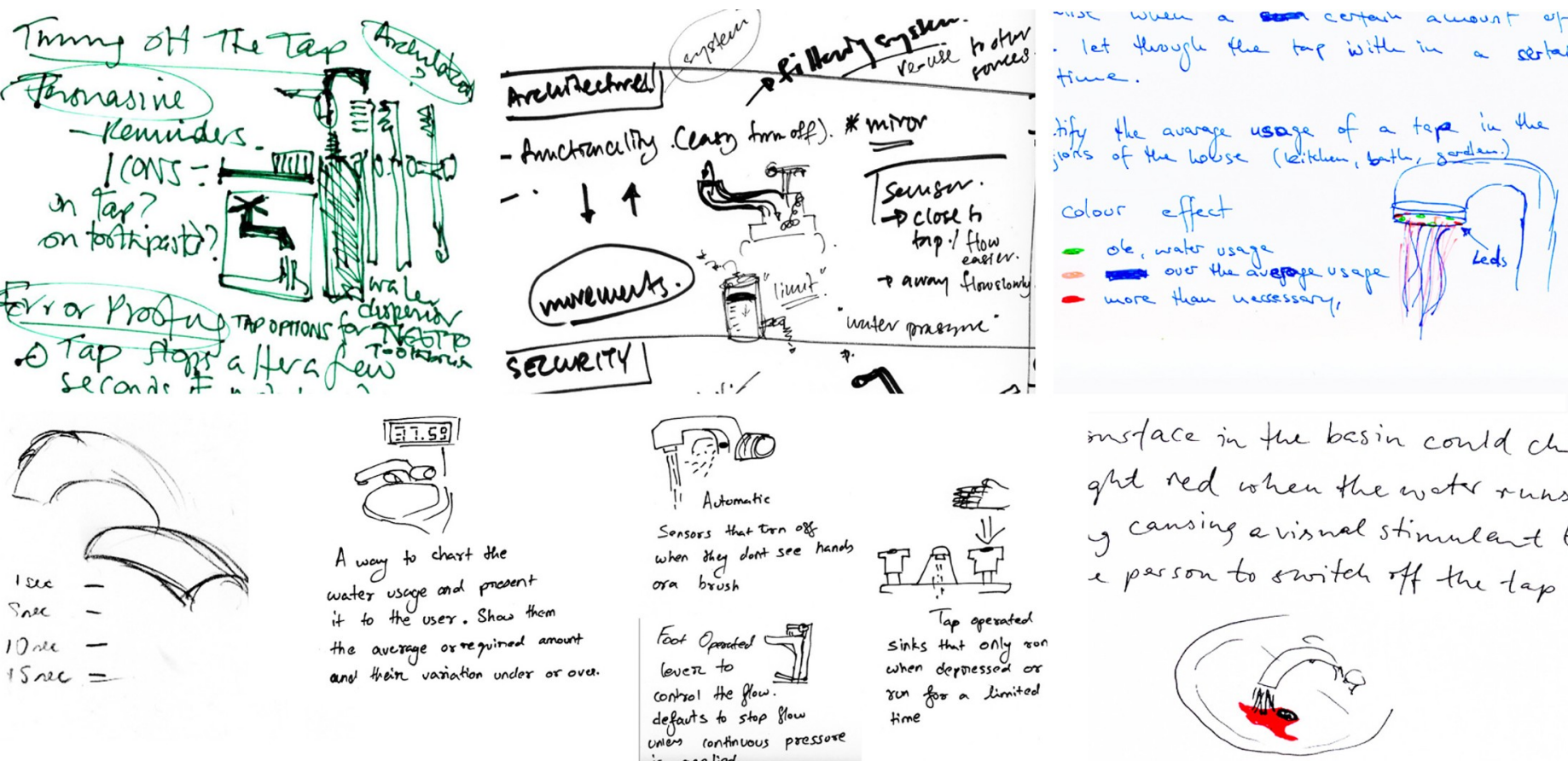

instace in the basin could ch ght red when the water runs $g$ cansing a vismal stimulent $t$ e person to switch off the tap

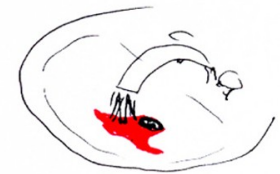

Figure 7. A selection of participants' sketches for B4 (the tap brief). 